PP23

\title{
TOWARDS AN OPTIMIZATION OF URBAN LIGHTING THROUGH A COMBINED APPROACH OF LIGHTING AND ROAD BUILDING ACTIVITIES
}

\author{
Valérie Muzet et al. \\ DOI 10.25039/x46.2019.PP23 \\ from \\ CIE x046:2019 \\ Proceedings \\ of the \\ 29th CIE SESSION \\ Washington D.C., USA, June 14 - 22, 2019 \\ (DOI 10.25039/x46.2019)
}

The paper has been presented at the 29th CIE Session, Washington D.C., USA, June 14-22, 2019. It has not been peer-reviewed by CIE.

(c) CIE 2019

All rights reserved. Unless otherwise specified, no part of this publication may be reproduced or utilized in any form or by any means, electronic or mechanical, including photocopying and microfilm, without permission in writing from CIE Central Bureau at the address below. Any mention of organizations or products does not imply endorsement by the CIE.

This paper is made available open access for individual use. However, in all other cases all rights are reserved unless explicit permission is sought from and given by the CIE.

CIE Central Bureau

Babenbergerstrasse 9

A-1010 Vienna

Austria

Tel.: +4317143187

e-mail: ciecb@cie.co.at

www.cie.co.at 


\title{
TOWARDS AN OPTIMIZATION OF URBAN LIGHTING THROUGH A COMBINED APPROACH OF LIGHTING AND ROAD BUILDING ACTIVITIES
}

\author{
Muzet, V. ${ }^{1}$, Colomb, M. ${ }^{2}$, Toinette, M. ${ }^{2}$, Gandon-Leger, P. ${ }^{3}$, Christory, J.P. ${ }^{4}$ \\ ${ }^{1}$ Cerema, Equipe projet ENDSUM, Strasbourg, FRANCE, \\ ${ }^{2}$ Cerema, Clermont-Ferrand, FRANCE, \\ ${ }^{3}$ AFE, Comatelec Schréder, Roissy, FRANCE, \\ ${ }^{4}$ Consultant, Rambouillet, FRANCE. \\ valerie.muzet@cerema.fr
}

DOI 10.25039/x46.2019.PP23

\begin{abstract}
The objective of this work is to develop tools and methods for managers, lighting designers and road builders to optimize lighting both in interurban and urban areas. The goal is a complete characterization of the photometry of a large pavement sample panel, according to the criteria usually used in lighting such as $Q_{0}$ and $S_{1}$ and a characterization with an observation angle more adapted to the urban environment. In this contribution, the results of the initial characterisation of the pavement sample panel at $1^{\circ}$ are presented.
\end{abstract}

Keywords: Road photometry, Road lighting design, Gonioreflectometer

\section{Introduction}

Designing a road lighting installation requires a combination of the photometric properties of the road surface and the optical characteristics of the luminaires to guarantee visual comfort for the driver while ensuring road safety and minimal energy consumption. Road lighting installations are designed by calculating the performance in terms of luminance distribution as defined in the EN13201 standard (CEN, 2015). Since the photometric characteristics of the pavements are generally not measured, a reference $r$-table as defined in (CIE, 1984); (CIE, 2001) is often used for lighting design.

The Pavement and Lighting working group ( $P \& L$ group or in French Revêtement et Lumière) is composed of project managers and public authoritiesa, professional associations and unions of lighting designers ${ }^{b}$ and road builders $c$, public and private research organisations ${ }^{d}$ and expert consultants. This working group was established on the basis of several observations.

- The reference CIE r-tables R1 to R4 that are used in France for lighting design are more than 70 years old and several studies have shown that these tables are no longer representative of actual pavements (Dumont, 2007a); (Dumont et al., 2007b); (Jacket et al., 2010); (Ylinen et al., 2010); (Petrinska et al., 2007); (Muzet et al., 2017); (Muzet et al., 2018). Their use can generate important errors (more than $30 \%$ ) for the average luminance (Chain et al., 2007).

- The lack of consideration for the real pavements characteristics may be due to the partitioning of professions between pavement and lighting actors who are not accustomed to work together. Indeed, few are the actors in the road sector who are specialists in the photometry of pavements and/or lighting and conversely, when renewing a lighting installation, the real characteristics of the road are rarely taken into account. In addition, the life cycles of the pavements and of the lighting installations are very different, which probably also explains the little interaction between the two professions.

\footnotetext{
a AITF Association des Ingénieurs Territoriaux de France

b AFE Association Française de l'Eclairage

C EUROBITUME, Office des Asphaltes, ROUTES DE France, SPECBEA (Spécialistes de la Chaussée en Béton Et des Aménagements), CIMbéton (Centre d'information sur le ciment et ses applications)

d Cerema (Centre d'Etudes et d'expertise sur les Risques, l'Environnement, la Mobilité et l'Aménagement), CERIB (Centre d'Etudes et de Recherches de I'Industrie du Béton).
} 
- Moreover, in urban areas, lighting renovations and road maintenance are often separate contracts, awarded and monitored by different departments.

- Today, the urban surfaces currently in use are characterised by a very rich range of techniques and finishing whose relevance is justified by the diversity of uses in the urban environment. There is also a significant potential for energy savings in the optimization of public lighting projects by considering the actual characteristics of the pavement. Indeed, what is important for the user is not the quantity of the luminous flux projected on a surface (illuminance), but the light reflected by the pavement or obstacle (luminance). The perception is made by contrast of object / background luminance (Blackwell, 1946) and this mainly depends on the reflective properties of the pavement, the light distribution of the luminaire and the user position. Last but not least, there was a major interest in moving from "doing as usual" to an optimal lighting.

- Nowadays, most of the lighting is urban and yet the standard EN 13201 observation angle is $1^{\circ}$ corresponding to a distance around $86 \mathrm{~m}$, which makes no sense for city driving where speeds are generally around 30 and $50 \mathrm{~km} / \mathrm{h}$ (Chain et al. 2008); (Stockmar, 2015); (Winter et al., 2016).

- However, technologies have evolved, both in terms of pavements and lighting solutions. This offers new opportunities, concerning the optimization of lighting design and the possibilities of retrofitting (Tardieu et al., 2017).

Since the Pavement and Lighting working group is composed of people of very different backgrounds (project managers, industrials organisations, research centres), it guarantees the ability to move from concept to practical applications. A first step consisted in organizing and monitoring demonstrators and operations on real sites to show the relevance of the challenges and concepts of optimal lighting; then to popularize the results and good practices (Abdo et al., 2010); (Batista et al., 2012); (Christory et al., 2014); (Muzet et al., 2018). The second step, presented here, consists in elaborating a library of actual and innovative pavements available on the French market to:

- facilitate the choice of lighting designers,

- develop tools and methods for managers, lighting designers and road builders to optimize lighting both in interurban and urban areas.

Our goal is a complete characterization of the photometry of a large pavement sample panel, according to the criteria usually defined in CIE144 (CIE, 2001) with the r-table, $Q_{0}$ and $S_{1}$ and in a next step, a characterization with an observation angle more adapted to the urban environment.

The collection of on-site photometric measurements will be an input for the European EMPIR SURFACE project (EMPIR, 2017); (lacumussi et al., 2017), which collects the $r$-tables of current and innovative road pavements across Europe in the context of a pre-normative study.

The paper is organized as follows. In the first part, we recall the basics of road lighting and describe the Cerema gonioreflectometer measuring device. Then we describe our selection of pavements and our analysis methodology. In the second part, the results of the study regarding road surface photometry are given and discussed in comparison with seventies data and more recent French data. The third part presents the first results of the lighting calculations.

\section{Methodology}

\subsection{Road lighting basics}

The reflection properties of the road surface are used for the computation of a lighting installation. The luminance coefficient $q$ of a surface element in a given direction, under specified conditions of illumination (Figure 1a) and an observation angle of $1^{\circ}$ is defined by

$$
q(\beta, \gamma)=L(\beta, \gamma) /\left(E_{h}\right)
$$

where $L$ is the observed luminance in $\mathrm{cd} / \mathrm{m}^{2}$ and $E_{\mathrm{h}}$ the horizontal illuminance in lux. 
The reduced luminance coefficient $r$ is defined by:

$$
r(\beta, \gamma)=10^{4} \times q(\beta, \gamma) \times \cos ^{3} \gamma
$$

The angle of observation $\alpha$ is set at $1^{\circ}$, which corresponds to a driver looking at about $90 \mathrm{~m}$. The $r$-table is a two-dimensional table with a number of standardized combinations of the incidence lighting angle $\gamma$ and orientation angle $\beta$, the boundaries of which define a solid angle $\Omega$. This table can be represented by a reflexion indicatrix as shown in Figure $1 \mathrm{~b}$. To simplify the description of photometric performance of road surfaces, the additional parameters $Q_{0}$ and $S_{1}$ can be calculated from the previous matrix as following

$$
\begin{aligned}
& Q_{0}=\int_{0}^{\Omega} \frac{q(\beta, \tan \gamma) \cdot d \Omega}{\Omega} \\
& S_{1}=\frac{r(\beta=0, \tan \gamma=2)}{r(\beta=0, \tan \gamma=0)} .
\end{aligned}
$$

$Q_{0}$ is the solid angle weighted average of all the luminance coefficients and is also called lightness (van Bommel, 2015) and the specularity factor $S_{1}$ represent the shininess of the pavement (see example of figure $2 b$ ).

a.

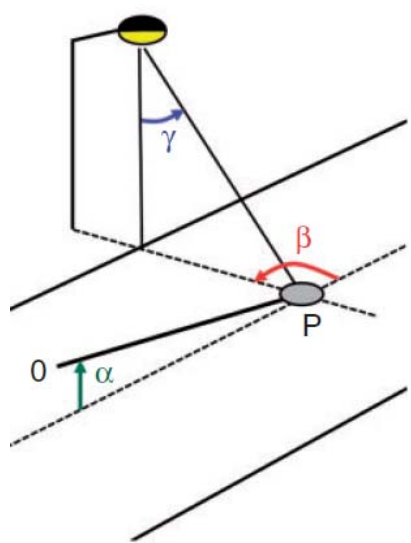

b.

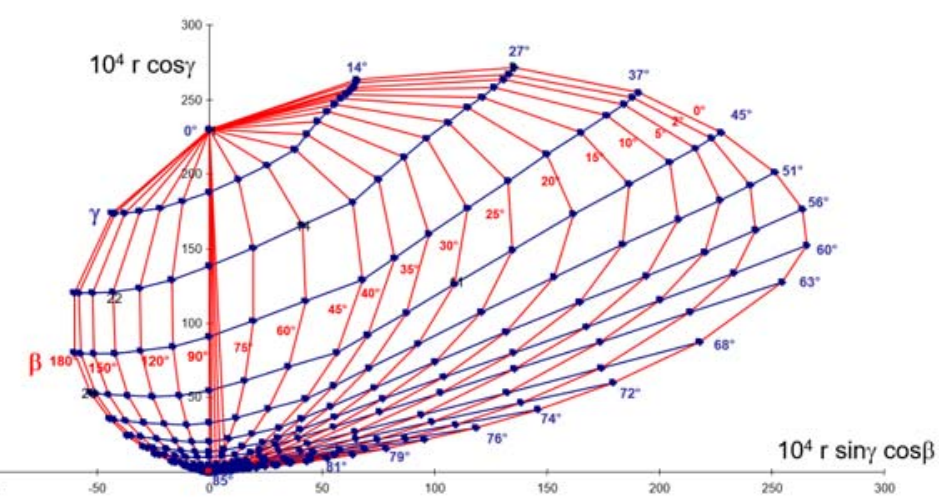

Figure $1-a$. The photometric characteristics of the road surface depend on the angles of observation $\alpha$, sight $\beta$ and incidence $\gamma .0$ represents the driver and $P$ the point of observation. b. Representation of a pavement reflection indicatrix (angle $\beta$ in red, angle $\gamma$ in blue).

Guidelines and road lighting standards in Europe give values for illuminance and luminance and their distribution on the road surface according to a grid of points whose number $\mathrm{N}$ depends on the pole spacing $S$ and number of traffic lanes (Figure 1a). The average luminance (Lave), overall luminance uniformity ratio $\left(U_{0}\right)$ and longitudinal luminance uniformity ratio $\left(U_{1}\right)$ are computed according to the standard specifications (CEN, 2015). 

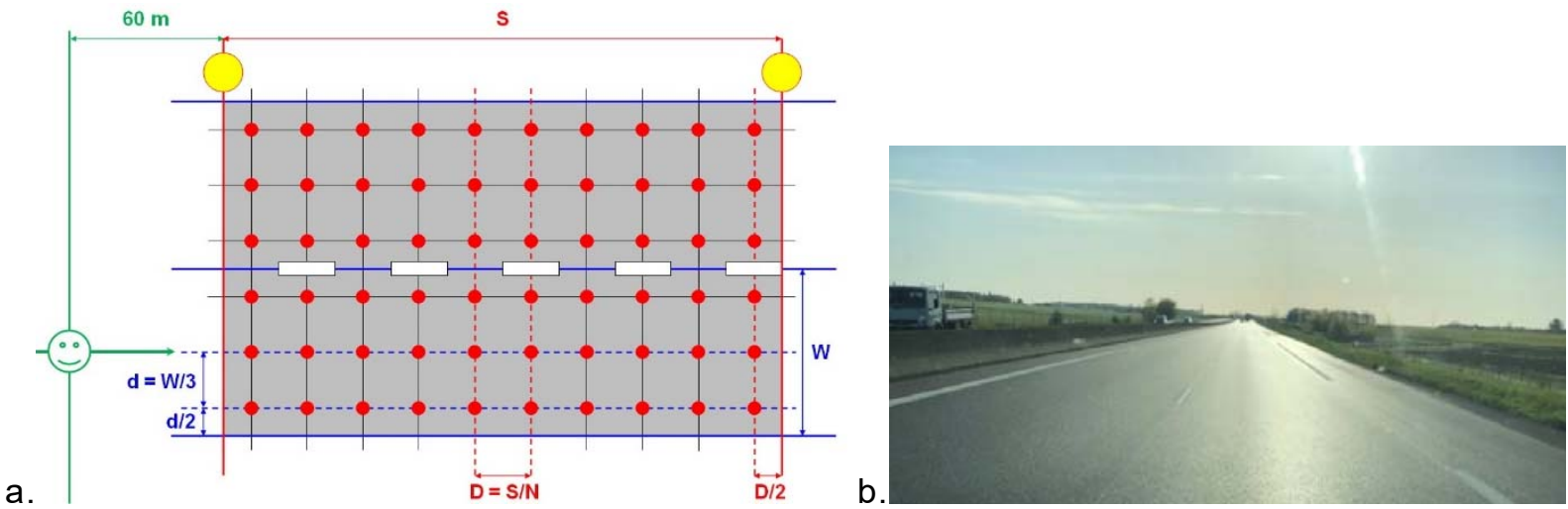

Figure 2 - a. Example of a calculation /measurement grid points (in red) in road lighting design/evaluation, according to the standard ( $w$ is the traffic lane width, $d$ the transversal distance between two lines of points and $D$ the longitudinal distance between two columns of points). b. Picture of a very specular road surface.

The CIE has defined different set of standard $r$-tables that are directly available in all lighting design software (CIE, 1984). Since 2001, the CIE144 (CIE, 2001) recommends a scaling of the chosen standard table according to the average luminance coefficient parameters $Q_{0}$. It is obvious that the design of a road lighting system should be based on the knowledge of the actual luminance coefficient for the actual road. Because the actual quantity of $q$ is not known, nor is listed as reference values in the EN standard (it provides only the directions in which $q$ should be known), designers use in the calculations as $q$ reference values the ones given in CIE 144 scientific publication. In France the CIE r-tables type R are mostly used.

\subsection{Description of the Cerema gonioreflectometer}

The Cerema gonioreflectometer in Clermont-Ferrand measures the reflection of road surfaces under the observation conditions of a motorist at an observation angle of $1^{\circ}$ according to $\mathrm{CIE}$ specifications. It gives the 580 reflected luminance coefficients $q(\beta, \gamma)$ of the r-table, and the parameters $Q_{0}$ and $S_{1}$.

The mechanical positioning unit consists of a steel base on which is adapted a rotating measuring arm to change the sight angle $\beta$ from 0 to $180^{\circ}$ and a light source positioning system to vary the angle of incidence of light $y$ from 0 to $90^{\circ}$ (see picture of Figure 3a). The mechanical movement system of the lamp and the arm carrying the photometer is computer controlled, so the data acquisition is fully automated.

The reference source is a type A halogen lamp (Philips PAR38 Spot bulb with a power of 120W, a nominal voltage of $24 \mathrm{~V}$, a nominal flow rate is $1545 \mathrm{Im}$ ) with a color temperature of $2700 \mathrm{~K}$ (warm light) and an angle of diffusion of $10^{\circ}$. The light source is a fixed on a metal arc with a radius of $2.05 \mathrm{~m}$, whose movement corresponding to the incidence angle is ensured by a motor connected to an indexer-transformer. The illuminated area is a $10 \times 10 \mathrm{~cm}$ square, always at the center of the sample.

The "sample holder device" consists of a turntable allowing to adjust the height of the sample, its lateral positioning and inclination to obtain the horizontality of the sample upper surface (Figure 3b). This allows the measurement area to be centered on the sample without having to change the luminance meter and source settings. 

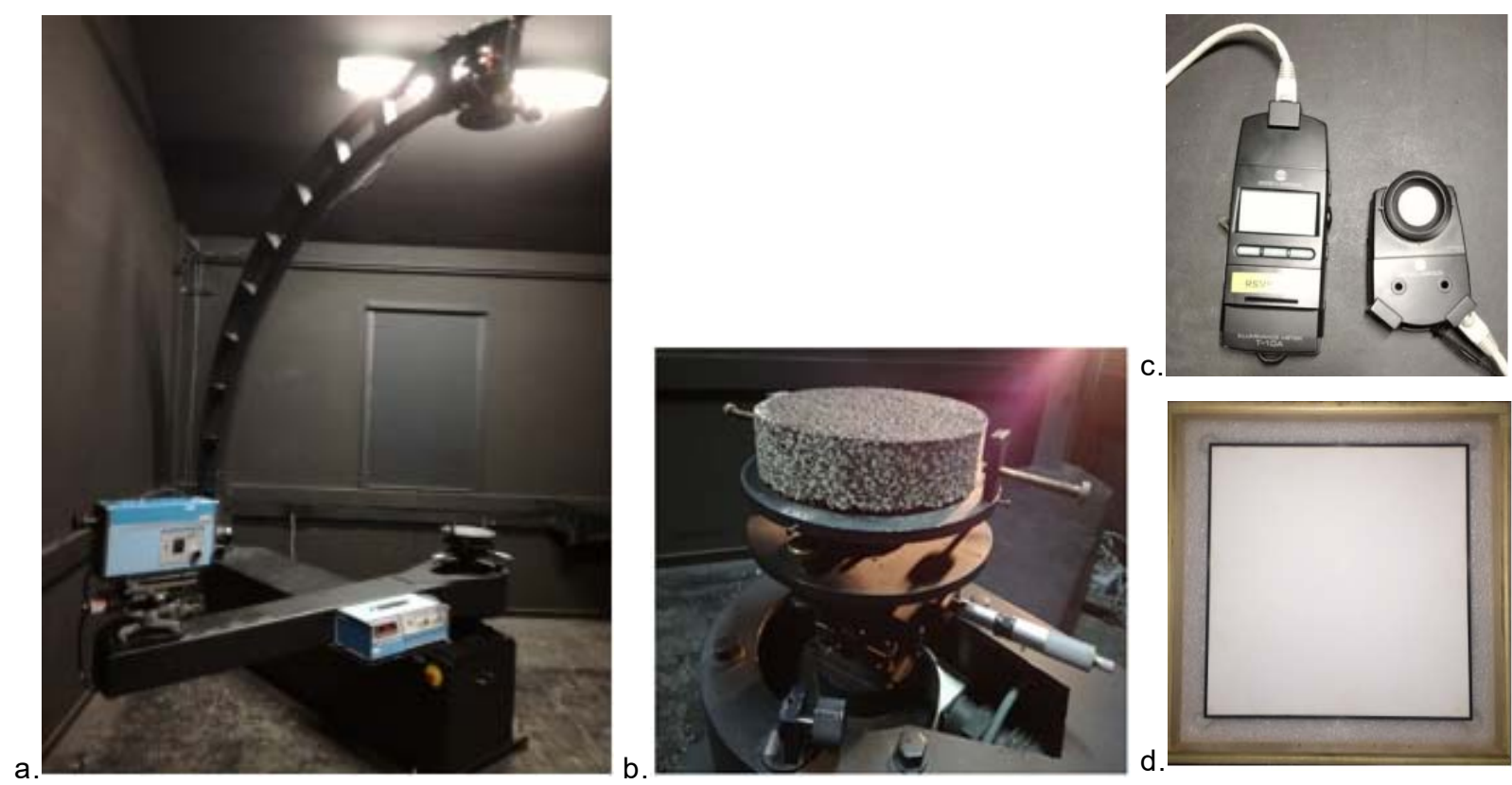

Figure 3 - Pictures of the Cerema gonioreflectometer with the Pritchard photometer (a), a sample of road pavement (b), the perfect diffuser used to check the reference luminance values (c) and the illuminancemeter to control the light source (d).

The luminance sensor is a Pritchard PR1980A Luminancemeter. It consists of the optical sensor and a control panel. The optical housing incorporates a trapezoidal diaphragm that precisely limits the measurement area to the projection of the $10 \times 10 \mathrm{~cm}$ square on the sample. It is equipped with a spectral luminous efficiency filter, $V(\lambda)$ as defined by the CIE. This sensor is fixed on an articulated arm, made of light alloy that is driven by a gear motor for the 20 positions of $\beta$ from 0 to $180^{\circ}$.

The electronic control unit includes an indexer-translator which, in conjunction with the microcomputer, controls the stepper motors of the source carriage and the turntable. A Labview program manages the control and data acquisition process and calculates the photometric parameters of the sample such as the luminance coefficient for all the angular combinations considered, the average luminance coefficient and the specular factors. The program ensures the presentation of the results in the form of a matrix of reduced luminance coefficients ( $r$-table) and its corresponding reflection indicatrix.

The measurement protocol is the following:

1. Measurement of the source level of illumination at the level of the measurement area on the sample with an illuminancemeter (picture on figure $3 \mathrm{c})$. The value $\left(E_{\mathrm{h}}\right.$ in the Equation (1)) is entered into the software for the calculation of the luminance coefficient.

2. Measurement of the luminance on a reference sample. A reference test is performed on a perfect diffuser (spectralon $99 \%$, picture on figure $3 \mathrm{~d}$ ) to check the luminance values and shape of the measured diffusion indicator, thus attesting correct functioning of the goniophotometer.

3. Then the test is carried out as follows: the lamp is in the first position (angle $y=0^{\circ}$ ), the arm rotates: the angle $\beta$ varies and luminance measurements are taken for $20 \beta$ values over a half turn (between 2 and $180^{\circ}$ ). The $y$ angle varies for its 29 positions and measurements are still taken each time for the 20 values of $\beta$, for a total of 580 values.

4. Finally, the software calculates complete r-table, then computes $Q_{0}, S_{1}$ and $S_{2}$. 


\subsection{The choice and characterisation of the pavements}

The first step was to establish a panel of urban and interurban surfacing that contains representative and innovative French technologies. This panel includes 35 different pavements used in roads and sidewalk with two samples for each pavements. These pavements are composed of more or less light aggregates.

- Bituminous pavements with classic or synthetic binder, including Very Thin Asphalt Concrete (VTAC) that are continuous or not and soft mastic asphalts. In the case of the synthetic binder, there is adding of $\mathrm{TiO}_{2}$. Some are raw pavements and others received an initial surface treatment like sandblasting. The aim of this initial surface treatment is to remove the bituminous layer to bring out the color of the aggregates.

- Cement concrete pavements and paving blocks. Again there are raw and treated surfaces. Different surface treatments were used (smooth, polished, brushed, shotblasted, sandblasted,...) to change the visual appearance and to give a better initial road skid resistance.

Our objective was to have a big variability to represent nowadays methodologies. There are 12 raw surfaces and 23 pavements with an initial surface treatment.

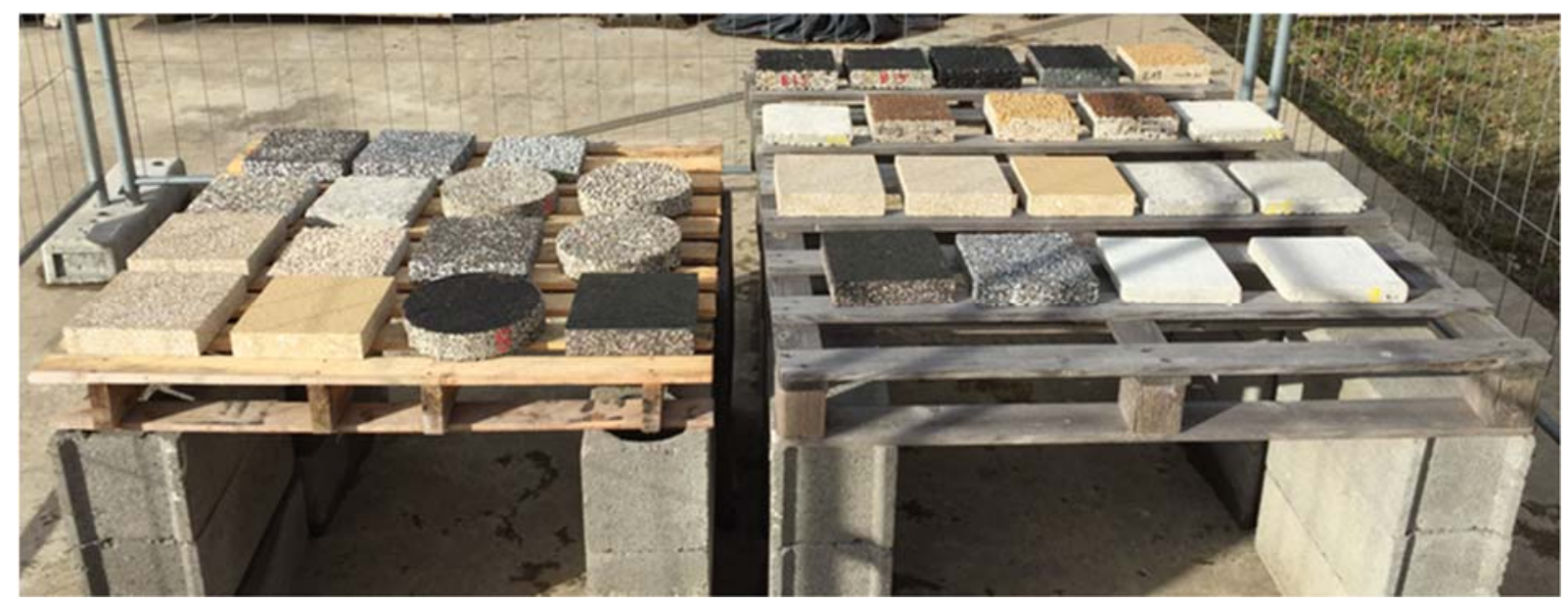

Figure 4 - Picture of the samples exposed outdoor

Half of the samples are stored in fridges and half of them are placed outdoor for natural ageing (Figure 4). The photometry of all the samples was characterized in their initial condition at the observation angle of $1^{\circ}$ with the Cerema's goniophotometer. A second series of measurements will be carried out after 3 years of ageing.

\subsection{The lighting computations}

The aim of the lighting calculations is to assess the impact of the use of the characteristics of actual surfaces. We compare all our calculations to the reference CIE r-table R3 (CIE, 1984), because it is used in France for lighting design and close to the CIE $r$-table C2, which is used in different European countries (Gidlund al., 2019). In order to assess the impact of the pavement and luminaire photometry, we propose several approaches:

- Case 1: Study of the effect of a measured pavement photometry compared to CIE r-table R3. The optimization of the lighting design is done with a CIE R3 pavement and comply with the EN 13201 standard. Then, without changing the luminaire, we calculate the effect of different actual pavement photometry for the average luminance, uniformities, and the Threshold Increment $T I$.

- Case 2: Study of the effect of a lighting renovation with an imposed geometry taking into account the actual pavement photometry. 
- Case 3: Complete optimization of the lighting design for a new road taking into account the actual pavement photometry. The lighting photometry and pole distance are optimized for each $r$-table.

Since the study is still going on, we focus here on 2 typical lighting installations proposed in the standard (CEN, 2015e) and a small set of pavements from our database with very different photometry. We choose LED for the lamps and the chosen lighting installation are:

- An interurban road with $2 \times 2$ lanes road for motorized traffic (road profile A) with the theoretical normative values of the lighting class $M 3$ class $\left(L_{\text {ave }}>=1.00 \mathrm{~cd} / \mathrm{m}^{2} ; U_{0}>0.40\right.$; $U_{1}>0.60, T I 10$, with no maintenance factor).

- A two-way traffic flow urban road with a sidewalk on the side of lighting arrangement (road profile $\mathrm{C}$ ) of with the theoretical normative values of the lighting class M4 class (Lave $>=0.75 \mathrm{~cd} / \mathrm{m}^{2} ; U_{0}>0.40 ; U_{1}>0.60, T I 15$, with no maintenance factor).

Table 1 - Input parameters for the lighting design

\begin{tabular}{|l|l|l|l|l|l|l|l|}
\hline & $\begin{array}{l}\text { Lighting } \\
\text { class }\end{array}$ & $\begin{array}{l}\text { Road } \\
\text { width }\end{array}$ & $\begin{array}{l}\text { Pole } \\
\text { height }\end{array}$ & $\begin{array}{l}\text { Pole } \\
\text { arrangement }\end{array}$ & $\begin{array}{l}\text { Pole road } \\
\text { side distance }\end{array}$ & $\begin{array}{l}\text { Lamp } \\
\text { tilt }\end{array}$ & $\begin{array}{l}\text { Lamp } \\
\text { spacinge }\end{array}$ \\
\hline Profile A & M3 & $7 \mathrm{~m}$ & $10 \mathrm{~m}$ & Opposite side & $5 \mathrm{~m}$ & $5^{\circ}$ & $40 \mathrm{~m}$ \\
\hline Profile C & M4 & $6 \mathrm{~m}$ & $8 \mathrm{~m}$ & Single side & $2 \mathrm{~m}$ & $5^{\circ}$ & $25 \mathrm{~m}$ \\
\hline
\end{tabular}

\section{Results}

\subsection{Concerning photometry}

The photometric characteristics of all the samples was measured in their initial condition (called "P\&L new" later on) with the Cerema's gonioreflectometer. The results of the measurements are presented in the Figure 4, and could be compared with all the typical CIE r-tables (R, C, N and $W$ for wet) (CIE, 2001), with an old database (Sorensen, 1975) of 285 measurements on samples mostly from the Nordic countries and also with the data of a French previous study (Dumont, 2007a). In this study, the photometry of VTAC road surfaces with no initial surface treatment was followed during 3 years with regular extraction of cores measured with the Cerema's gonioreflectometer.

The initial measurements done on the P\&L pavement samples show a high variability in the photometric characteristics of the pavements and confirm, as in other studies that the typical CIE tables are not representative of nowadays pavements (Dumont et al., 2007b); (Jacket et al., 2010); (Ylinen et al., 2010); (Petrinska et al., 2007); (Muzet et al., 2017); (Muzet et al., 2018) and have a greater variability than the Sorensen study (Sorensen, 1975). It shows the huge influence of raw material and treatments as well on the photometric characteristics.

e Imposed for case 1 and 2 


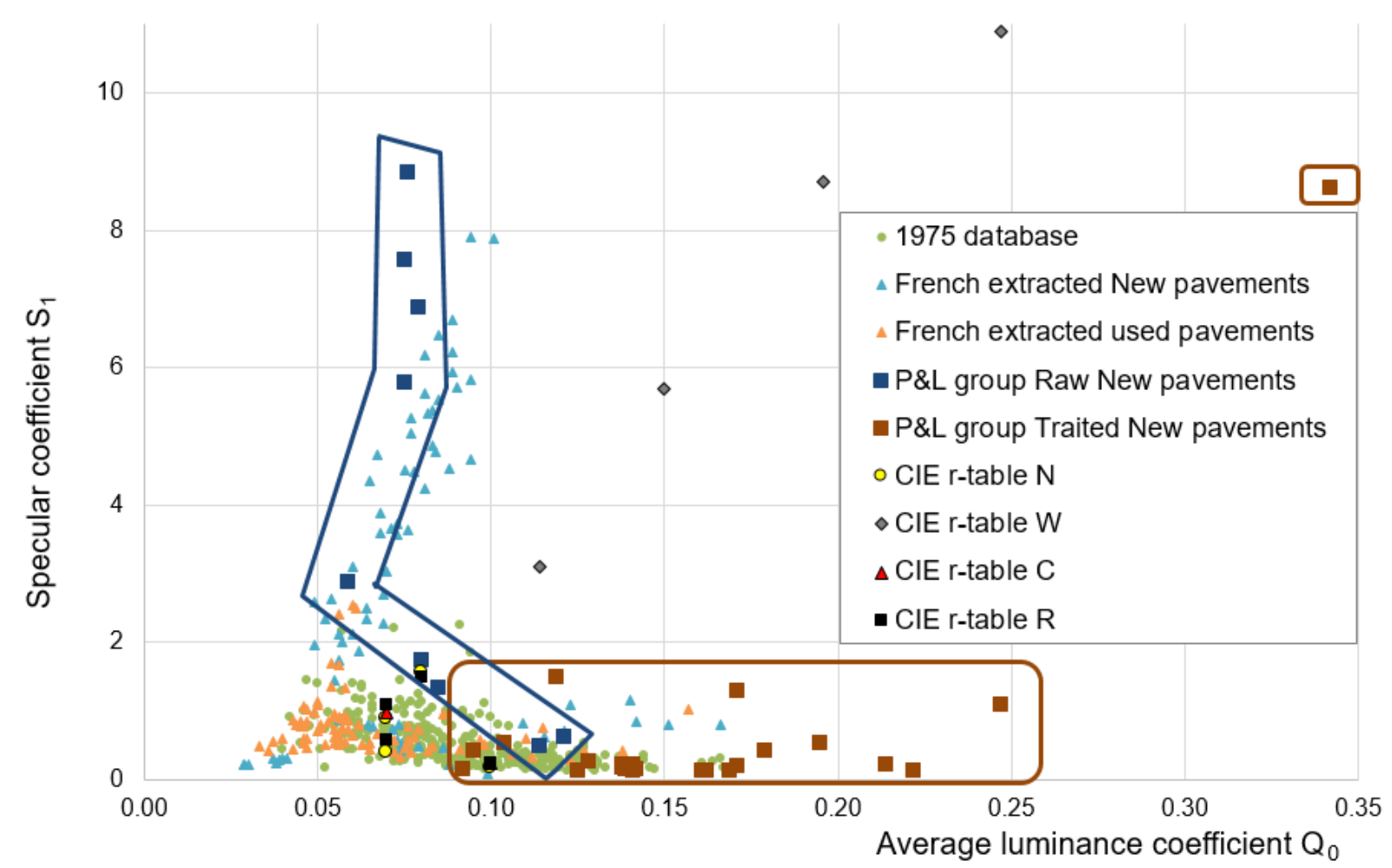

Figure 5 - Representation of the P\&L initial measurements for raw pavements (dark blue squares), initially treated ones (brown squared). Sorensen 1975 data are in green circles, the French new pavements in light blue triangles and the used ones in pink triangle. The reference CIE r-tables are also presented.
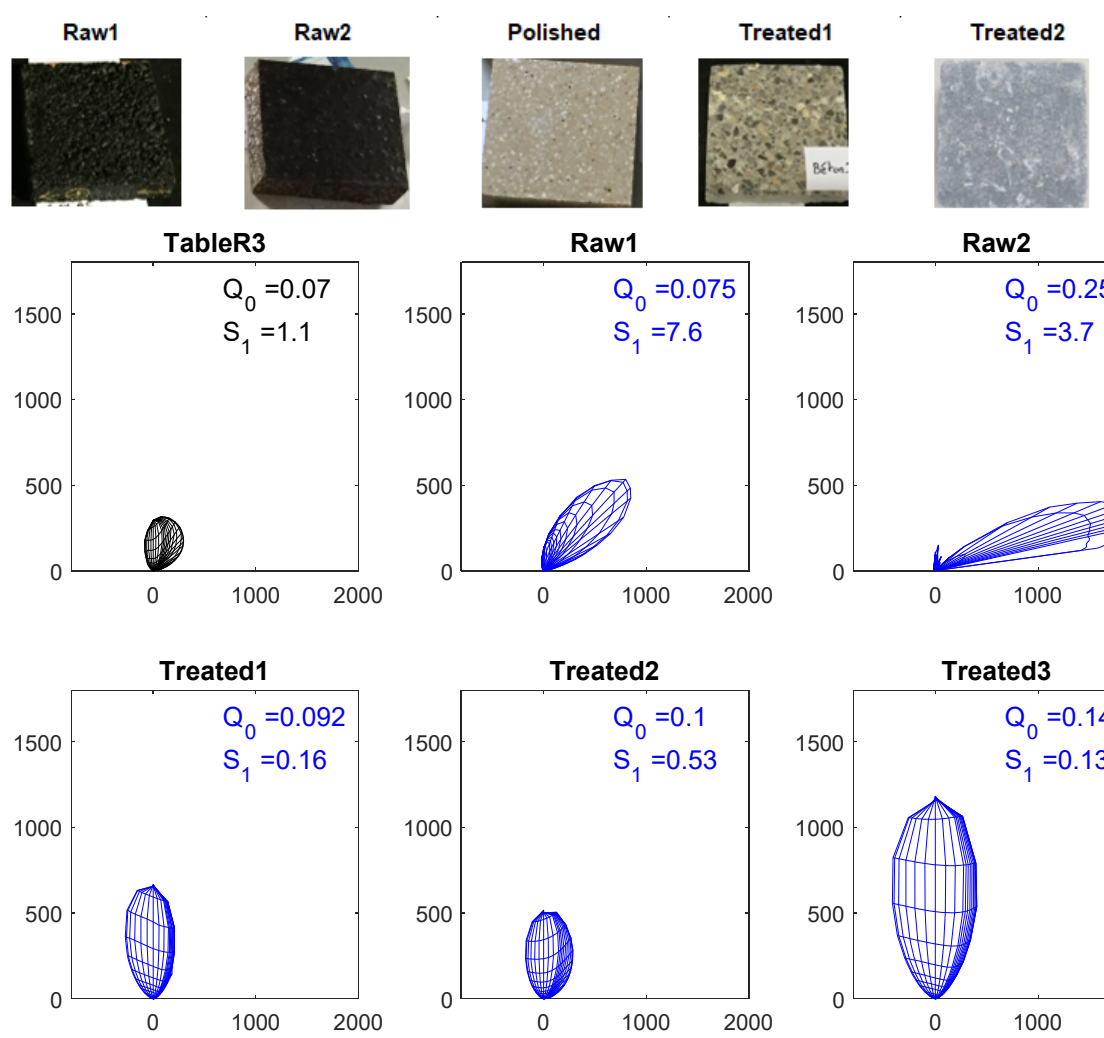

Raw2
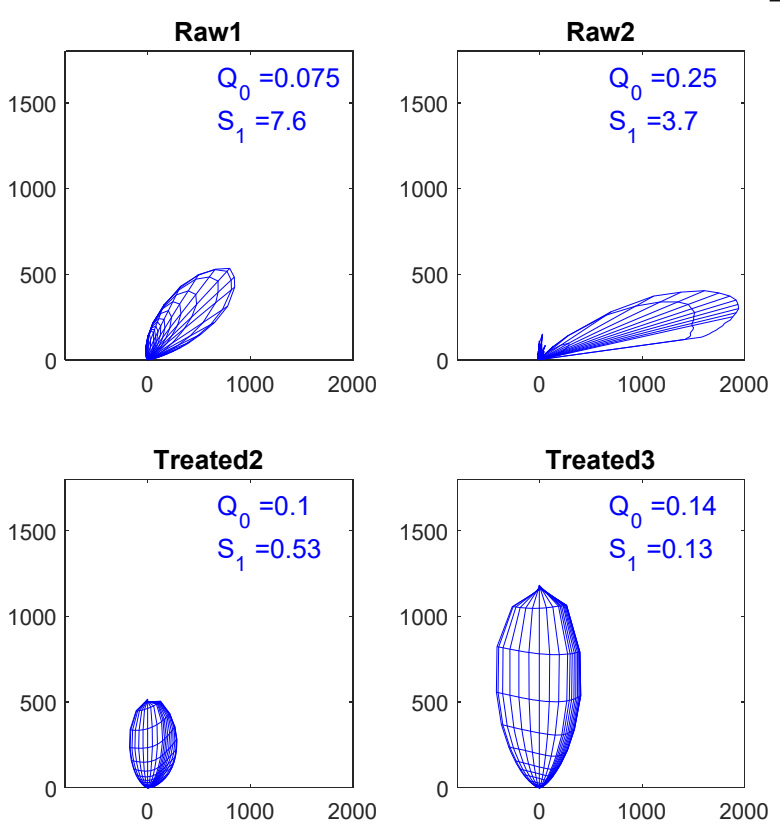
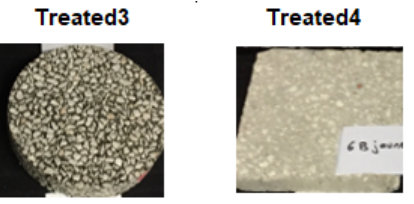

Polished
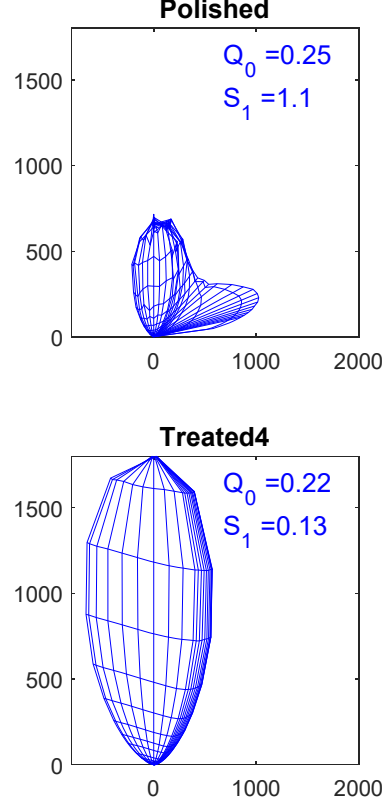

Figure 6 - Pictures of the selected samples. Representation of the pavement reflection indicatrix of the CIE r-table R3 in black and in blue of the selected $r$-tables of our database of initial characterisation. We have two raw pavements with a high specularity, a polished one and also four initially treated surface. 
Our results obtained with the raw pavements (dark blue) are in accordance with the measurements done on the French extracted core of the new pavements with a high specularity (light blue). We measured very specular behaviour on some of our new samples, close to the CIE r-tables W (CIE, 2001), representative of wet pavements.

For our P\&L samples of initially treated surfaces, we obtained a lower specularity and for some samples a high Q. We confirm, as in (Muzet et al., 2018), that surface processing sharply decreases the specularity of new pavements.

To validate our lighting design protocol, we selected extreme pavements from our database to study their effect on lighting design and energy consumption. A picture and their reflexion indicatrix is presented in the figure 6 , in comparison with the CIE r-table R3.

\subsection{Concerning lighting design}

The results of the case 1 lighting design that assess the effect of an actual pavement in a lighting design done with CIE reference R3 is presented in the table 2.

- For the type A road with M3 theoretical normative values $\left(L_{\text {ave }}>=1.00 \mathrm{~cd} / \mathrm{m}^{2} ; U_{0}>0.40\right.$; $\left.U_{1}>0.60 ; T K 10\right)$, the optimised design for a LED lamp and type R3 reference pavements gives a power of $46.7 \mathrm{~W}$, a flux of $7100 \mathrm{~lm}$, and an illuminance of $13.5 \mathrm{lux}$.

- For the type C road with M4 theoretical normative values $\left(L_{\text {ave }}>=0.75 \mathrm{~cd} / \mathrm{m}^{2} ; U_{0}>0.40\right.$; $\left.U_{1}>0.60 ; T K 15\right)$, the optimised design for a LED lamp and type R3 reference pavements gives a power of $20.6 \mathrm{~W}$, a flux of $3200 \mathrm{Im}$, and an illuminance of $11.1 \mathrm{lux}$.

Table 2 - Results of case1 lighting design: Impact of actual photometry for the two road profiles. When the standard requirement is not fulfilled, the figures are in red.

\begin{tabular}{|c|c|c|c|c|c|c|c|c|c|}
\hline & & \multirow{2}{*}{\begin{tabular}{|c|} 
Reference \\
CIE R3 type
\end{tabular}} & \multicolumn{7}{|c|}{ Name of pavement } \\
\hline & & & Raw1 & Raw2 & Polished & Treated 1 & Treated2 & Treated3 & Treated 4 \\
\hline \multirow{2}{*}{$\begin{array}{c}\text { Pavement } \\
\text { Photometry }\end{array}$} & $Q_{0}$ & 0.07 & 0.08 & 0.25 & 0.25 & 0.09 & 0.10 & 0.14 & 0.22 \\
\hline & $S_{1}$ & 1.11 & 7.57 & 3.74 & 1.10 & 0.16 & 0.53 & 0.13 & 0.13 \\
\hline \multirow{5}{*}{$\begin{array}{c}\text { Class M3 } \\
\text { Power } 46.7 \mathrm{~W} \text {, } \\
\text { Flux } 7100 \mathrm{Im} \text {, } \\
\text { Illuminance } \\
13.5 \text { lux }\end{array}$} & $L_{\text {ave }}$ & 1.00 & 1.48 & 1.05 & 2.31 & 1.26 & 1.37 & 1.95 & 3.02 \\
\hline & $U_{0}$ & 0.43 & 0.21 & 0.05 & 0.34 & 0.51 & 0.52 & 0.47 & 0.49 \\
\hline & $U_{I}$ & 0.62 & 0.26 & 0.17 & 0.55 & 0.57 & 0.75 & 0.49 & 0.50 \\
\hline & $T I$ & 12.0 & 8.7 & 11.5 & 1 & 10.0 & 9.3 & 7.0 & 4.9 \\
\hline & \begin{tabular}{|c|}
$\begin{array}{c}\text { Fulfill } \\
\text { M3 }\end{array}$ \\
\end{tabular} & Fully & None & None & None & None & Fully & None & None \\
\hline \multirow{5}{*}{$\begin{array}{c}\text { Class M4 } \\
\text { Power } 20.6 \mathrm{~W} \text {, } \\
\text { Flux } 3200 \mathrm{Im} \text {, } \\
\text { Illuminance } \\
11.1 \text { lux }\end{array}$} & $L_{\text {ave }}$ & 0.77 & 1.08 & 2.44 & 1.80 & 0.85 & 1.07 & 1.58 & 1.01 \\
\hline & $U_{0}$ & 0.46 & 0.20 & 0.56 & 0.38 & 0.04 & 0.57 & 0.55 & 0.58 \\
\hline & $U_{I}$ & 0.85 & 0.71 & 0.56 & 0.69 & 0.23 & 0.81 & 0.57 & 0.63 \\
\hline & $T I$ & 8.3 & 6.3 & 3.3 & 4.2 & 7.7 & 6.4 & 4.7 & 6.7 \\
\hline & \begin{tabular}{|c|}
$\begin{array}{c}\text { Fulfill } \\
\text { M4 }\end{array}$ \\
\end{tabular} & Fully & None & None & None & None & Fully & None & Fully \\
\hline
\end{tabular}

These calculations show quite similar results for both type of roads.

When the lighting design is optimised for a CIE reference $\mathrm{R}$ table (R3 in our case) to comply with the standard, the impact of the actual photometry of new pavements is very high.

For very specular pavements like in our case Raw1, Raw2 and Polished pavements, we do not respect the standard at all, especially for both uniformities, with a percentage error that could reach $90 \%$ for $U_{0}$ et $70 \%$ for $U_{1}$. 
In our calculation based on new pavements, we had classic and also very light pavements. We obtain an overestimation of luminance that could even reach $200 \%$ and in the case of the treated2 pavement for example we overpass the required uniformity specifications.

As in (Chain, 2007); (Christory, 2014); (Muzet, 2018), (Gidlund, 2019), these results confirm the importance of measuring and taking into account the actual photometry of pavements. The impact of initial treatment is good because it decreases the specularity and then, the uniformities are closer to the standard requirements.

Calculations of case 2 and 3 are still ongoing and their results are not available yet.

\section{Conclusions}

The initial measurements done on the "Pavement and Lighting group" pavement samples show a high variability in the photometric characteristics of the pavements. Our results confirm that the CIE standard $r$-tables are not representative of actual French pavements. In particular, the impact of surface processing on initial photometry is very significant and with the use of light aggregates and initial treatments, it is possible to have diffuse material with high $Q_{0}$. With the use of a standard $r$-tables, the standard requirements are not fulfilled and this could generate safety problems. The contribution of the use of specific pavements to achieve energy savings will be studied in the next steps of the study and is very promissing.

Another measurement will be done after 3 years at $1^{\circ}$ and $10^{\circ}$ characterizations will be carried out in new and aged condition. Indeed, $10^{\circ}$ corresponds to an observation distance of $8.5 \mathrm{~m}$, which could be relevant in an urban environment for drivers when they are close to intersections, cyclists and pedestrians. An adaptation of the lighting design will also be proposed, taking into account this new geometry.

At the end of our study, a catalogue will be presented in the form of files for managers and lighting designers and road builders. We will propose a technical pavement sheet, that could be used by pavements builders, lighting designers and infrastructure managers. It will contain a pavement description, initial and after 3 year photometric characteristics in the $1^{\circ}$ and $10^{\circ}$ geometry and also usage and maintenance recommendations.

With the constitution of a measurement database of actual pavements and the proposal of new lighting designed adapted to different uses in urban environment, this project will contribute to the CIE TC 4.50 (Road surface characterization for lighting applications) and the Empir SURFACE project (EMPIR, 2017); (lacumussi, 2017).

\section{Aknowledgements}

We would like to thanks Joseph Abdo (CIMbéton), Frédérico Batista (CD 78), Maël Buannic (Office des asphaltes), Salah Boussada (AITF/MEL), Jérôme Dherbecourt (Routes de France/EIFFAGE Routes), Sophie Jacob (CERIB), Thibaut Le Doeuff (CERIB), Christine Leroy (Routes de France), Romain Lafon (Routes de France/EUROVIA), Emmanuel Loison (Routes de France/COLAS), and Florence Pero (SPECBEA).

\section{Fundings}

This project received financial support of the "Pavement and Lighting group" members. Part of this work received funding from the EMPIR programme project "16NRM02 Surface Pavement surface characterisation for smart and efficient road lighting". EMPIR programme is co-financed by the Participating States and from the European Union's Horizon 2020 research and innovation program. 


\section{References}

ABDO, J., BATISTA, F., CARRE, D., CHRISTORY J.P., DEPETRINI A., PERET, M. 2010. Démarche innovante Revêtements et lumière, de l'idée à la pratique, $R G R A, 885$ (in french).

BATISTA, F., CHRISTORY, J.P., TALBOURDET, Y., TAQUET, K. 2012. Groupe Revêtements et lumière ; travail sur le coût global pour changer les habitudes, RGRA, 904, (in french).

BLACKWELL, H. 1946. Contrast Thresholds of the Human Eye. In: Journal of the Optical Society of America, Vol. 36, Issue 11, pp. 624-643.

CHRISTORY, J.P., BATISTA, F., GANDON-LEGER, P., TALBOURDET. 2014. Pavements and light for the right lighting: contribution of concrete pavements, In: Eupave symposium on concrete roads, Praha, CZ.

CEN 2015a. CEN 13201-1:2015. Road lighting - Part 1: Selection of lighting classes.

CEN 2015b. CEN 13201-2:2015. Road lighting - Part 2: Performance requirements.

CEN 2015c. CEN 13201-3:2015. Road lighting - Part 3: Calculation of performance.

CEN 2015d. CEN 13201-4:2015. Road lighting - Part 4: Methods of measuring light performance.

CEN 2015e. CEN 13201-4:2015. Road lighting - Part 5: Energy performance indicators.

CHAIN C, LOPEZ F AND VERNY P., 2007, Impact of real road photometry on public lighting design. In: 26th session of the CIE, Beijing, China.

CHAIN, C., MARCHAUT, V. 2008, R-tables for other observation angles: specific needs for two applications in the field of public lighting. CIE 2008.

CHAIN, C., VERNY, P., MUZET, V., GREFFIER, F. 2015. Optimization of road surfaces reflection properties and lighting. In: 28th session of the CIE, Manchester, United Kingdom.

CIE 1984. CIE 066-1984. Road Surfaces and lighting, joint CIE/PIARC publication.

CIE 2000. CIE 140-2000. Road Lighting Calculations, Technical Report.

CIE 2001. CIE 144-2001. Road surface and road marking reflexion characteristics, Technical Report.

DUMONT, E. 2007a. Photométrie des chaussées et éclairage public, In : Etudes et Recherches des laboratoires des ponts et chaussées, CR45, LCPC (eds), p.82 (in french).

DUMONT, E., PAUMIER, J.L. 2007b. Are standard tables R still representative of the properties of road surfaces in France? In: 26th session of the CIE, Beijing, China.

EMPIR 2017. 16NRM02 Surface Pavement surface characterisation for smart and efficient road lighting, European EMPIR project 2017-2020, http://surface-nrm02.eu/.

IACOMUSSI, P., ROSSI, G., BLATTNER, P., et al. 2017. Metrology of road surface for smart lighting. In: LUX EUROPE, Ljubljana 2017, $103-107$.

GIDLUND, H., LINDGREN, M., MUZET, V., ROSSI G, IACOMUSSI, P. 2019. Road surface photometric characterisation and its impact on energy savings. Coatings, 9(5), 286; https://doi.org/10.3390/coatings9050286.

JACKETT, M., FRITH, W. 2010. Reflection properties of New Zealand road surfaces for road lighting design. In: IPENZ Transportation Group Conference, Christchurch, New Zealand, $14 \mathrm{p}$.

MUZET, V., GREFFIER, F., NICOLAÏ, A., TARON, A., VERNY, P. 2018. Evaluation of the performance of an optimized road surface/lighting combination. Lighting Research and Technology , first published on line, DOI: 10.1177/1477153518808334

MUZET, V., ABDO, J. 2017. On site photometric characterisation of concrete pavements with COLUROUTE device. In: Lux Europa, Ljubljana, Slovenia, pp.164-168. 
PETRINSKA, D., IVANOV, D., DAVLOV, D., et al. 2015. Road surface reflection properties of typical for Bulgaria pavement materials, In: Lux Junior, Dörnfeld, Germany.

SÖRENSEN, K. 1975. Report 10. In Road Surface Reflection Data. The Danish Illuminating Engineering Laboratory, Lyngby, Denmark.

STOCKMAR, A. 2015, Extension of the luminance concept in road and tunnel lighting, In: 28th session of the CIE, Manchester, United Kingdom.

TARDIEUX, P., GREFFIER, F., TARON, A. 2017. Projet Lumiroute ${ }^{\circledR}$, Evaluation du système EQflux, RGRA, 950: 18-21 (in French).

YLINEN, A., PUOLAKKA, M., HALONEN, L. 2010. Road surface reflection properties and applicability of the r-tables for today's pavement material in Finland, Light and Engineering, 18(1): 78-90.

VAN BOMMEL, W. 2015. Road Lighting: Fondamental, Technology and Application, In : Springer International Publishing Switzerland (eds), p.334.

WINTER, J., FOTIOS, S., VÖLKER, S., 2016. Gaze direction when driving after dark on main and residential roads: Where is the dominant location? Lighting Research and Technology (Online First), DOI:10.1177/1477153516632867. 